http://economix.fr

\title{
Inflation Targeting and the Forward Bias Puzzle in Emerging Countries
}

Document de Travail Working Paper 2017-12
Dramane Coulibaly Hubert Kemp 


\title{
Inflation Targeting and the Forward Bias Puzzle in Emerging Countries*
}

\author{
Dramane Coulibaly $^{a}$ Hubert Kempf ${ }^{b \dagger}$ \\ ${ }^{a}$ EconomiX-CNRS, University Paris Nanterre \\ ${ }^{b}$ Ecole Normale Supérieure Paris Saclay and CREST
}

This version: March 13, 2017

\begin{abstract}
Based on quarterly data on 31 emerging countries (among which 16 are inflation targeting countries) from 1990Q1 to 2014Q3, we obtain a strong support for the conjecture that the implementation of inflation targeting weakens the Fisherian relation between expected depreciation and the interest rate differential (uncovered interest parity condition) and thus is conducive to the appearance of the forward bias puzzle in emerging countries. We show that this reflects the performance of inflation targeting regimes in lowering the level and volatility of inflation which leads non-Fisherian fundamentals to be predominant. Our finding holds when controlling for country-specific effects, time-specific effects, global disinflation, exchange rate management and using different econometric techniques.
\end{abstract}

Keywords: Inflation targeting, uncovered interest parity, forward bias puzzle, emerging countries

JEL classification: E31, E52, F31

${ }^{*}$ We thank seminar participants at CREST and Centre d'économie de la Sorbonne for their remarks on a preliminary version. We are grateful to Valérie Mignon for helpful comments. The usual disclaimer applies.

${ }^{\dagger}$ Corresponding author: Hubert Kempf, Ecole Normale Supérieure Paris Saclay, 61 boulevard du Président Wilson, 94235 Cachan cedex. E-mail address: hubert.kempf@enscachan.fr. 


\section{Introduction.}

After being initiated by New Zealand in 1990, inflation targeting (hereafter IT $)^{1}$ has been adopted by a large number of industrial and emerging countries as a strategy to conduct monetary policy. Several studies have found evidence that adopting an IT strategy has lead to overall economic performance (Bernanke and Mishkin, 1997; Svensson, 1997; Mishkin and Schmidt-Hebbel, 2007). More specifically, the adoption of IT by some emerging countries has helped to reduce the level and volatility of inflation in these countries (Gonçalves and Salles, 2008; Lin and Ye, 2009; De Mendonça and Guimarães e Souza, 2012).

The contribution of this paper is to examine the impact of IT on the uncovered interest parity (hereafter UIP) condition through the reducing effect of IT on inflation uncertainty in emerging countries. The forward bias puzzle (hereafter FBP) referring to the failure of UIP to hold is well documented (Fama, 1984; Bansal and Dahlquist, 2000; Chinn and Meredith, 2004; Ito and Chinn, 2007; Frankel and Poonawala, 2010; Farhi and Gabaix, 2016). The forward premium puzzle (hereafter FPP) (i.e. a negative correlation between the expected currency depreciation and interest rate differential reflecting) which is an extreme form of the FBP occurs in developed economies but not in emerging countries. This feature is explained by the high level of inflation uncertainty in the latter ones (Bansal and Dahlquist, 2000 and Frankel and Poonawala, 2010). More specifically, as noticed by Bansal and Dahlquist (2000), the absence of FPP in emerging countries is consistent with the reasoning developed in models incorporating non-Fisherian effects (Lucas, 1990; Fuerst, 1992). In these models, in presence of high inflation uncertainty or high expected inflation the Fisherian effects are overwhelming. However, in low inflation environments, the non-Fisherian fundamentals can be predominant. As emerging economies display large inflation uncertainty and/or high expected inflation the Fisherian relation between expected depreciation and the interest rate differential holds. As a result, the FPP is absent. On the contrary, as developed countries are generally low inflation economies, the non-Fisherian effects are important, leading to the FPP. Recently, Farhi and

\footnotetext{
${ }^{1}$ Following the literature inflation targeting is defined as a framework characterized by the five components listed by Mishkin (2000): "1) the public announcement of mediumterm numerical targets for inflation; 2) an institutional commitment to price stability as the primary goal of monetary policy, to which other goals are subordinated; 3) an information inclusive strategy in which many variables, and not just monetary aggregates or the exchange rate, are used for deciding the setting of policy instruments; 4) increased transparency of the monetary policy strategy through communication with the public and the markets about the plans, objectives, and decisions of the monetary authorities; and 5) increased accountability of the central bank for attaining its inflation objectives."
} 
Gabaix (2016) develop a disaster-based tractable framework for the analysis of exchange rates and show that the UIP tends to be hold in countries with very variable inflation (typically countries with high average inflation). Based on this reasoning and evidence, we conjecture that, by lowering inflation uncertainty, the adoption of IT in some emerging countries can lead to the appearance in these countries of the forward bias puzzle, in contrast with the non-adopting IT emerging countries. We test this conjecture in this paper.

To this end, we conduct an empirical investigation using quarterly data on 31 emerging countries (among which 16 are IT countries) from 1990Q1 to 2014Q3. Our results are consistent with the conjecture that IT strongly modifies the pattern of interest rates determination which reverberates on the behavior of exchange rates. Specifically, we find that the implementation of IT in emerging countries expand the FBP, i.e., weakens the Fisherian relation between expected depreciation and the interest rate differential (UIP condition). We show that this reflects the fact that IT helps lowering inflation level and volatility which renders non-Fisherian fundamentals predominant in the determination of the exchange rates. This finding holds after controlling for country-specific effects, time-specific effects, global disinflation and exchange rate management. It still holds when we use alternative econometric techniques.

The rest of the paper is organized as follows. Section 2 provides the theoretical background on the link between inflation targeting and the FBP. Section 3 describes the data used in the empirical estimation. Section 4 presents the empirical analysis and discusses the results obtained. Finally, Section 5 gives concluding comments.

\section{Inflation targeting and forward bias puzzle in emerging countries.}

\subsection{The Fama regression.}

Given open international bond markets, the no-arbitrage condition of covered interest parity (hereafter CIP) requires

$$
f_{t}^{k}-s_{t}=i_{t}^{k}-i_{U S, t}^{k}
$$

where $s_{t}$ is the logarithm of the spot exchange rate at time $t$ expressed as the domestic currency per unit of the foreign currency (the US dollar), $f_{t}^{k}$ represents the logarithm of the corresponding forward rate set at time $t$, 
payable at $t+k ; i_{t}^{k}$ and $i_{U S, t}^{k}$ denote the nominal interest rates observed at time $t$ on $k$-period maturity risk-free bonds in domestic currency and the U.S. dollar, respectively.

The CIP condition implies the equality between the forward discount rate and the interest rate differential. Thus, any premium in the forward discount rate must be reflected in the interest rate differential. The forward premium $\left(f_{t}^{k}-s_{t}\right)$ is related to the expected depreciation $\left(E\left(\Delta s_{t}^{k} \mid I_{t}\right) \equiv E\left(s_{t+k} \mid I_{t}\right)-s_{t}\right)$ and the forward risk premium $\left(f_{t}^{k}-E\left(s_{t+k} \mid I_{t}\right)\right)$ as follows:

$$
f_{t}^{k}-s_{t}=E\left(\Delta s_{t}^{k} \mid I_{t}\right)+f_{t}^{k}-E\left(s_{t+k} \mid I_{t}\right)
$$

where $E($.$) is the expected value operator and I_{t}$ is the set of information available at time $t$. The forward premium is the sum of the expected currency depreciation $E\left(\Delta s_{t}^{k} \mid I_{t}\right)$ and the forward risk premium $f_{t}^{k}-E\left(s_{t+k} \mid I_{t}\right)$. Therefore, given the forward premium, information on the expected depreciation (forward risk premium) suffices to restrict the forward risk premium (respectively, expected depreciation). Under the assumption that the forward risk premium is null (the forward exchange rate is equal to the expected exchange rate), we obtain the uncovered interest parity (UIP) condition:

$$
E\left(\Delta s_{t}^{k} \mid I_{t}\right) \equiv E\left(s_{t+k} \mid I_{t}\right)-s_{t}=i_{t}^{k}-i_{U S, t}^{k}
$$

In absence of data on market expectations of future exchange rate (particularly in our case of emerging countries), assuming rational expectations is a commonly used solution for testing UIP (Equation (3)). Under the assumption of rational expectations, the ex post realized change in the exchange rate is given by

$$
\Delta s_{t}^{k} \equiv s_{t+k}-s_{t}=\left(i_{t}^{k}-i_{U S, t}^{k}\right)+v_{t}^{k}
$$

where $v_{t}^{k}=s_{t+k}-E\left(s_{t+k} \mid I_{t}\right)$ is a white noise error that is uncorrelated with information available at time $t\left(I_{t}\right)$.

In an econometric perspective, the following regression model, called the "Fama regression", is considered:

$$
\Delta s_{t}^{k}=\alpha+\beta\left(i_{t}^{k}-i_{U S, t}^{k}\right)+\varepsilon_{t}^{k}, t=1, \ldots, T
$$

Under UIP, the intercept $\alpha=0$, the slope parameter $\beta=1$, and the error term $\varepsilon_{t}^{k}$ (the rational expectations forecast error under the null hypothesis) must be uncorrelated with any information known at time $t$ (Fama, 1984).

The rejection of UIP condition (specifically $\beta \neq 1$ ), or equivalently the forward bias puzzle (FBP), is well documented (Fama, 1984; Bansal and Dahlquist, 2000; Chinn and Meredith, 2004; Ito and Chinn, 2007; Frankel 
and Poonawala, 2010). Empirical studies often find a negative $\beta$. The finding of a negative $\beta$ has counter-intuitive implications and is referred to as the forward premium puzzle (FPP). As shown by Fama (1984), the departure from $\beta$ equal to one implies a time-varying risk premium. He noticed that the slope-coefficient, $\beta$, in Equation (5) is equal to $\operatorname{Cov}\left(d_{t}^{k}, d_{t}^{k}+p_{t}^{k}\right) / \operatorname{Var}\left(d_{t}^{k}+p_{t}^{k}\right)$ where $d_{t}^{k}$ denotes the expected currency depreciation $\left(d_{t}^{k}=E\left(\Delta s_{t}^{k} \mid I_{t}\right)\right)$, and $p_{t}^{k}$ is the forward risk premuim $\left(p_{t}^{k}=f_{t}^{k}-E\left(s_{t+k} \mid I_{t}\right)\right)$. Thus, the finding of a negative slope-coefficient implies that the risk premium is more volatile than the expected depreciation, while a slope-coefficient bigger than one implies the opposite. More importantly, the finding of a negative slope-coefficient implies that the aggregate risk in the economy (the volatility of the intertemporal marginal rate of substitution) must be lower when the level of interest rate is high (Bansal, 1997).

A few studies have tried to explain the FBP. Bansal and Dahlquist (2000) investigate whether the forward bias is related to macroeconomic fundamentals (income, inflation, country risk) that characterize the cross-sectional dispersion in the risk premium. Using data on 28 developed and emerging countries, they find that the FPP is not a pervasive phenomenon because it is confined to high income economies. Specifically, they obtain evidence that countries with lower per capita income, higher inflation uncertainty and high credit risk rating have larger slope coefficients. This result is consistent with the explanation put forward in models incorporating nonFisherian effects (Lucas, 1990 ; Fuerst, 1992). In these models, in presence of high inflation uncertainty or high expected inflation the Fisherian effects are present and overwhelming. However, in low inflation environments, the non-Fisherian fundamentals can dominate. Therefore, in emerging and low income economies characterized by large inflation uncertainty, the forward discount should point in the right direction (the FPP should be absent). On the contrary, in developed countries which are generally low inflation economies, the non-Fisherian effects are important, leading to the FPP. In other words, as noticed by Frankel and Poonawala (2010), it should be easier to forecast the direction of movement of the spot rate (through UIP relation) in emerging economies, more prone to high inflation, than in developed countries for which the exchange rate behavior is closer to a random walk. Recently, Farhi and Gabaix (2016) build a disaster-based tractable framework for the analysis of exchange rates and point out that the UIP tends to be hold in countries with very volatile inflation (typically countries with high average inflation). 


\subsection{Can inflation targeting be conducive to the for- ward bias puzzle in emerging countries?}

A monetary strategy such as IT has the objective of obtaining a low-inflationary environment. It is with such an objective that many emerging countries adopted IT. We conjecture that, if it proves effective, the implementation of a low-inflation environment by means of IT should be conducive to the forward bias puzzle and may lead to the appearance or the reinforcement of the FBP, for the same reason as in the developed countries, summarized above.

Empirical studies confirm that IT is conducive to a low-inflation environment (both in level and in variance) in emerging countries. To control for mean reversion, Ball and Sheridan (2006) use a difference-difference approach on 20 industrial countries and do not find a contribution of IT in reducing the level and the volatility of inflation. On the contrary, employing the same approach on a subset of 36 emerging economies, Gonçalves and Salles (2008) found that IT was instrumental in reducing inflation level and volatility. To address the self-selection problem of policy adoption, Vega and Winkelried (2005) employ the propensity score matching (PSM) technique on data from 109 countries (23 inflation targeting countries) over the period 1990 to 2004 and find that IT has helped in reducing the level and volatility of inflation. Employing also the PSM treatment effect on 22 industrial countries (7 inflation targeting countries) for the period 1985 to 1999, Lin and Ye (2007) do not find significant lowering impact of IT on either inflation or inflation variability. On the contrary, using the same methodology on 52 developing countries (13 inflation targeting countries) over the period 1985 to 2005, Lin and Ye (2009) find evidence that IT has large and significant lowering impact on both inflation level and inflation variability. De Mendonça and Guimarães e Souza (2012) extend the PSM methodology on a sample of 180 countries for the period from 1990 to 2007 and find that the adoption of IT has contributed to the decrease in both inflation and its volatility solely in developing countries. To sum up, there is strong evidence that adopting IT has lowered both the level and variance of inflation in emerging countries.

Given this set of evidence, it is reasonable to infer, in line with Bansal and Dahlquist (2000), that for the emerging countries which have adopted IT, the forward bias should increase, as the Fisherian relation between expected depreciation and the interest rate differential is weakened just as in developed countries. This is the conjecture that we test here. 


\section{Data.}

We use quarterly data from 31 emerging countries (see Table 1 for the list of countries). These countries are selected based on data availability. The sample period covered is from 1990Q1 to 2014Q3. Among these countries, 16 have implemented inflation targeting. For each of these targeters, the adoption dates are reported in Table 1. As in Bansal and Dahlquist (2000), so as to assess the forward premium interest rate differentials are obtained by subtracting the interest rate for each country from the U.S. Eurodollar rate (LIBOR rate). When available, we use interbank rates. For some countries for which such interest rates are not available, we consider bank deposit rates instead. Based on data availability, we consider 3-month and 1-year maturity interest rates acquired from Datastream. The data on spot exchange rates are expressed as the domestic currency per unit of the foreign currency and are drawn from the IMF's International Financial Statistics. The data on annual inflation rates are also taken from the IMF's International Financial Statistics. To characterize exchange rate regimes, we rely on the Reinhart and Rogoff de facto exchange rate regime (coarse) classification updated by Ilzetzki et al. (2011). ${ }^{2}$

Table 1 reports the mean and the volatility (standard deviation) of the inflation rate for targeters before and after IT and for non-targeters before and after 2000. The year 2000 is used as demarcation date for non-targeters since it corresponds to the average adoption date of IT. Table 1 shows that the initial level of inflation and its volatility were very high in targeting countries before adopting IT. There is a drastic decrease in the level and the volatility of inflation in all countries with a larger magnitude in targeting countries. This is in line with the results from the aforementioned studies examining the performance of IT. These studies find that, even controlling for mean reversion, emerging countries that have adopted IT have experienced greater reductions in inflation level and inflation volatility. The next section reports the results of the empirical estimation examining whether this reducing impact on inflation and its volatility is reflected in the Fama regression.

\section{Empirical analysis and results.}

In order to do so, we proceed as follows. We adopt a panel data approach since, as evidenced by Baillie and Bollerslev (2000), univariate time series

\footnotetext{
${ }^{2}$ Data are available at http://www.carmenreinhart.com/data/browse-by-topic/ topics/11/.
} 
Table 1: Inflation

\begin{tabular}{|c|c|c|c|c|c|}
\hline & \multirow[b]{2}{*}{ Adoption } & \multicolumn{2}{|c|}{ Inflation Mean } & \multicolumn{2}{|c|}{ Inflation volatility } \\
\hline & & Before IT/2000 & After IT/2000 & Before IT/2000 & After IT/2000 \\
\hline Brazil & $1999 \mathrm{q} 2$ & 887.41 & 6.51 & 1056.87 & 2.48 \\
\hline Chile & 1991q1 & 25.19 & 5.62 & 1.91 & 4.78 \\
\hline Colombia & $1999 \mathrm{q} 4$ & 22.15 & 5.10 & 5.52 & 2.11 \\
\hline Czech Republic & $1997 \mathrm{q} 4$ & 9.12 & 2.90 & 0.55 & 2.47 \\
\hline Hungary & $2001 q 2$ & 20.53 & 4.66 & 7.75 & 2.20 \\
\hline Indonesia & $2005 \mathrm{q} 3$ & 12.27 & 6.95 & 12.63 & 2.74 \\
\hline Israel & $1991 q 4$ & 18.09 & 4.61 & 0.98 & 4.14 \\
\hline Korea & $1997 q 4$ & 6.13 & 3.01 & 1.80 & 1.52 \\
\hline Mexico & $1998 \mathrm{q} 4$ & 20.83 & 5.52 & 9.49 & 3.22 \\
\hline Peru & $1999 \mathrm{q} 3$ & 828.53 & 2.72 & 2281.71 & 1.27 \\
\hline Philippines & $1999 \mathrm{q} 3$ & 9.31 & 4.38 & 3.94 & 1.55 \\
\hline Poland & $1998 \mathrm{q} 3$ & 93.64 & 3.54 & 169.31 & 2.70 \\
\hline Romania & $2005 q 3$ & 88.21 & 5.12 & 84.34 & 2.00 \\
\hline South Africa & 2001q1 & 9.39 & 5.91 & 3.43 & 2.40 \\
\hline Thailand & $2000 \mathrm{q} 2$ & 4.80 & 2.61 & 2.05 & 1.60 \\
\hline Turkey & $2006 q 1$ & 60.01 & 8.33 & 27.23 & 1.33 \\
\hline All targeters & $1999 q 4$ & 133.55 & 4.68 & 229.87 & 2.58 \\
\hline Argentina & - & 252.91 & 9.06 & 697.61 & 6.29 \\
\hline Bulgaria & - & 188.58 & 5.13 & 307.43 & 3.58 \\
\hline China & - & 7.75 & 2.29 & 8.02 & 2.01 \\
\hline Croatia & - & 232.11 & 2.70 & 526.14 & 1.46 \\
\hline Egypt & - & 10.49 & 8.23 & 5.68 & 4.24 \\
\hline Hong Kong & - & 6.87 & 1.26 & 4.37 & 2.90 \\
\hline India & - & 9.55 & 6.87 & 2.84 & 2.88 \\
\hline Malaysia & - & 3.66 & 2.25 & 0.87 & 1.20 \\
\hline Morocco & - & 4.44 & 1.63 & 2.36 & 0.95 \\
\hline Pakistan & - & 9.72 & 8.67 & 2.59 & 4.63 \\
\hline Russia & - & 222.23 & 11.64 & 288.93 & 4.76 \\
\hline Singapore & - & 1.94 & 2.05 & 1.24 & 1.91 \\
\hline Sri Lanka & - & 11.25 & 9.20 & 4.51 & 4.97 \\
\hline Taiwan & - & 2.88 & 1.07 & 1.41 & 1.10 \\
\hline Venezuela & - & 47.44 & 25.93 & 21.15 & 12.28 \\
\hline All non-targeters & & 67.45 & 6.53 & 125.01 & 2.80 \\
\hline
\end{tabular}

Note: For "All targeters" and "All non-taregters", the statistics are computed using the sample of targeters and non-targeters, respectively. 
would lead to inconsistent results. Indeed, the interest rate differential being very persistent, the standard asymptotic distribution for the slope-coefficient is a very poor approximation for small samples. Hence using panel data mitigates this inference problem (Bansal and Dahlquist, 2000). Moreover, the panel data approach tackles the data limitation problem that is important for emerging countries.

We first proceed by including IT into the Fama regression. Then we conduct various robustness analysis and thorough investigations.

\subsection{Including inflation targeting into the Fama regres- sion.}

In order to examine the influence of IT on FBP, we include IT into the Fama regression and we test the following equation ${ }^{3}$ :

$$
\Delta s_{i t}^{k}=\alpha_{i}+\beta\left(i_{i t}^{k}-i_{U S, t}^{k}\right)+\phi_{I T} I T_{i t} *\left(i_{i t}^{k}-i_{U S, t}^{k}\right)+\varepsilon_{i t}^{k}
$$

where $i=1, \ldots, N$ is country index, $\alpha_{i}$ denotes the country fixed effects, $I T_{i t}$ is a dummy variable taking the value of 1 if country $i$ is under inflation targeting at time $t$ and 0 otherwise. For some countries, scholars disagree on the adoption date of inflation targeting regime. For these countries, we use as the adoption dates of inflation targeting strategy the "default dates" obtained by Rose (2007) that are based on a best judgment of when inflation targeting began (see Section 3) .

The impact of interest rate differential on expected depreciation is $\beta+$ $\phi I T$ ( $\beta$ for non-targeters and $\beta+\phi$ for targeters). If the coefficient $\phi$ is significant and negative, it is consistent with the conjecture made above, that IT inflation targeting weakens the UIP condition, thus increases the forward bias and may lead to the FPP.

The estimation results of Equation (6) are reported in Table 2. The estimated slope coefficient $(\hat{\beta})$ of Fama regression is 0.597 and 0.410 using 3 -month and 1-year maturities, respectively. In both cases, the estimate is significant at $1 \%$ level. Our finding of an average positive value less than unity in emerging countries is in line with previous studies (Bansal and Dahlquist, 2000; Frankel and Poonawala, 2010) showing that the FBP is present in emerging countries with the forward discount pointing in the right direction.

As conjectured above, the forward bias may be large in emerging countries that have adopted IT. This conjecture is corroborated by including in the Fama regression the interaction between this IT dummy and the interest

\footnotetext{
${ }^{3}$ Preliminary diagnostic tests show ex post depreciation $\left(\Delta s_{i t}^{k}\right)$ and interest rate differential $\left(i_{i t}^{k}-i_{U S, t}^{k}\right)$ do not exhibit an unit root.
} 
rate differential. Indeed, whatever the maturity used, the coefficient of this interaction term is negative and highly significant. The results in columns (3) and (7), without control for country fixed effects, show that adopting IT increases the forward bias: the slope-coefficient for non-targeters is positive $(1>\hat{\beta}>0)$, while for targeters this coefficient is lower and still positive $(1>\hat{\beta}>\hat{\beta}+\hat{\phi}>0)$. However, when we control for both time and country effects in columns (4) and (8), the results show that adopting IT seems lead to the occurrence of FPP: the slope coefficient for non-targeters is still positive, but the coefficient for targeters becomes negative $(\hat{\beta}+\hat{\phi}<0)$.

To sum up, we confirm that the FBP is present in emerging countries with the forward discount pointing in the right direction, but we show the implementation of IT increases the extent of the FBP in emerging countries and may lead these countries to be prone to the FPP (the forward discount pointing in the wrong direction) as in developed countries.

\subsection{Controlling for global disinflation.}

As shown in Table 1, the beginning of the 21st century was characterized by global disinflation, i.e. a downward trend in inflation in all countries. Global disinflation can influence the UIP relation as well as IT. To check that the impact of IT does not reflect global disinflation, we introduce as additional regressor the interaction of the interest rate differential with a dummy variable characterizing the disinflation episode. We define its beginning as year 2000 (the average adoption date of IT). Thus we introduce a new dummy, denoted by $D 2000$, then equals 0 before 2000, 1 otherwise. We therefore consider the following regression:

$$
\begin{aligned}
\Delta s_{i t}^{k}= & \alpha_{i}+\beta\left(i_{i t}^{k}-i_{U S, t}^{k}\right)+\phi_{I T} I T_{i t} *\left(i_{i t}^{k}-i_{U S, t}^{k}\right) \\
& +\phi_{D I S I N F} D 2000_{i t} *\left(i_{i t}^{k}-i_{U S, t}^{k}\right)+\varepsilon_{i t}^{k}
\end{aligned}
$$

where $\phi_{I T}$ and $\phi_{D I S I N F}$ are expected to be negative. In this specification, the impact of the interest rate differential on expected depreciation is $\beta+\phi_{D I S I N F}$ for non-targeters and $\beta+\phi_{I T}+\phi_{D I S I N F}$ for targeters.

Table 3 reports the estimation of Equation (7) in which we control for the potential influence of global disinflation. In this robustness analysis, the influence of IT is present for any maturity, while global disinflation increases the forward bias $\left(\hat{\phi}_{D I S I N F}<0\right)$ based only on 1-year maturity but not up to the appearance of the FPP for non-targeters $\left(\hat{\beta}+\hat{\phi}_{\text {DISINF }}>0\right)$. Whatever the maturity considered, the adoption of IT combined with global disinflation reinforces the FBP in emerging countries to such an extent that the FPP 
Table 2: Inflation targeting and the Fama regression

\begin{tabular}{|c|c|c|c|c|}
\hline \multicolumn{5}{|c|}{ Dependent variable: Ex post currency depreciation } \\
\hline & \multicolumn{4}{|c|}{ 3-month } \\
\hline & $(1)$ & $(2)$ & $(3)$ & $(4)$ \\
\hline$\left(i-i_{U S}\right)$ & $\begin{array}{c}0.597^{* * *} \\
(0.079)\end{array}$ & $\begin{array}{c}0.531^{* * *} \\
(0.154)\end{array}$ & $\begin{array}{c}0.612^{* * * *} \\
(0.079)\end{array}$ & $\begin{array}{c}0.474^{* * *} \\
(0.141)\end{array}$ \\
\hline$I T \times\left(i-i_{U S}\right)$ & & & $\begin{array}{c}-0.457^{* * *} \\
(0.087)\end{array}$ & $\begin{array}{c}-0.726^{* * *} \\
(0.161)\end{array}$ \\
\hline Const. & $\begin{array}{c}5.322 \\
(3.620)\end{array}$ & $\begin{array}{c}5.676 \\
(3.665)\end{array}$ & $\begin{array}{c}5.162 \\
(3.624)\end{array}$ & $\begin{array}{c}6.222 \\
(3.734)\end{array}$ \\
\hline Obs. & 2,303 & 2,303 & 2,303 & 2,303 \\
\hline Time effects & Yes & Yes & Yes & Yes \\
\hline \multirow[t]{3}{*}{ Country effects } & No & Yes & No & Yes \\
\hline & \multicolumn{4}{|c|}{ 1-year } \\
\hline & $(5)$ & $(6)$ & $(7)$ & $(8)$ \\
\hline$\left(i-i_{U S}\right)$ & $\begin{array}{c}0.410 * * * \\
(0.071)\end{array}$ & $\begin{array}{c}0.304^{* * *} \\
(0.090)\end{array}$ & $\begin{array}{c}0.423^{* * *} \\
(0.073)\end{array}$ & $\begin{array}{c}0.281^{* * *} \\
(0.089)\end{array}$ \\
\hline$I T \times\left(i-i_{U S}\right)$ & & & $\begin{array}{c}-0.270^{*} \\
(0.147)\end{array}$ & $\begin{array}{c}-0.508^{* *} \\
(0.199)\end{array}$ \\
\hline Constant & $\begin{array}{c}0.739 \\
(1.943)\end{array}$ & $\begin{array}{c}6.811 \\
(5.299)\end{array}$ & $\begin{array}{c}0.661 \\
(1.914)\end{array}$ & $\begin{array}{c}6.611 \\
(5.250)\end{array}$ \\
\hline Observations & 1,961 & 1,961 & 1,961 & 1,961 \\
\hline Time effects & Yes & Yes & Yes & Yes \\
\hline Country effects & No & Yes & No & Yes \\
\hline $\begin{array}{l}\text { Notes: IT is a du } \\
\text { geting countries, } \\
\text { parentheses. For } \\
\text { White heteroskeda } \\
\text { rity regression, sta } \\
\text { autocorrelation-con } \\
\text { at } 10 \% \text { and } 1 \% \text { lev }\end{array}$ & $\begin{array}{l}\text { amy variabl } \\
\text { nd } 0 \text { other } \\
3 \text {-month ma } \\
\text { ticity-consis }\end{array}$ & $\begin{array}{l}\text { taking a va } \\
\text { ise. Robus } \\
\text { urity regres } \\
\text { nt standard } \\
\text { re Newey-W } \\
\text { rd errors. * }\end{array}$ & $\begin{array}{l}\text { ue of } 1 \text { for } \\
\text { standard e } \\
\text { ion, standar } \\
\text { errors ; for } \\
\text { st heterosker }\end{array}$ & $\begin{array}{l}\text { flation tar- } \\
\text { rors are in } \\
\text { errors are } \\
\text {-year matu- } \\
\text { asticity and } \\
\text { significance }\end{array}$ \\
\hline
\end{tabular}

occurs in these countries $\left(\hat{\beta}+\hat{\phi}_{I T}+\hat{\phi}_{\text {DISINF }}<0\right)$. Therefore, our finding that adopting IT weakens the UIP relation in emerging countries holds even when controlling for global disinflation. 
Table 3: Inflation targeting and the Fama regression, controlling for global disinflation

\begin{tabular}{|c|c|c|c|c|}
\hline & \multicolumn{2}{|c|}{ 3-month } & \multicolumn{2}{|c|}{ 1-year } \\
\hline & $(1)$ & $(2)$ & $(3)$ & $(4)$ \\
\hline$\left(i-i_{U S}\right)$ & $\begin{array}{c}0.474^{* * *} \\
(0.141)\end{array}$ & $\begin{array}{c}0.468^{* * *} \\
(0.140)\end{array}$ & $\begin{array}{c}0.281^{* * *} \\
(0.089)\end{array}$ & $\begin{array}{c}0.407^{* * *} \\
(0.081)\end{array}$ \\
\hline$I T \times\left(i-i_{U S}\right)$ & $\begin{array}{c}-0.726^{* * *} \\
(0.161)\end{array}$ & $\begin{array}{c}-0.744^{* * *} \\
(0.192)\end{array}$ & $\begin{array}{c}-0.508^{* *} \\
(0.199)\end{array}$ & $\begin{array}{c}-0.442^{* *} \\
(0.195)\end{array}$ \\
\hline$D 2000 \times\left(i-i_{U S}\right)$ & & $\begin{array}{c}0.051 \\
(0.271)\end{array}$ & & $\begin{array}{c}-0.317^{* *} \\
(0.125)\end{array}$ \\
\hline Constant & $\begin{array}{c}6.222 \\
(3.734)\end{array}$ & $\begin{array}{c}6.277 \\
(3.726)\end{array}$ & $\begin{array}{c}6.611 \\
(5.250)\end{array}$ & $\begin{array}{l}8.427^{*} \\
(5.041)\end{array}$ \\
\hline Obs. & 2,303 & 2,303 & 1,961 & 1,961 \\
\hline Time effects & Yes & Yes & Yes & Yes \\
\hline Country effects & Yes & Yes & Yes & Yes \\
\hline $\begin{array}{l}\text { Notes: IT is a dumn } \\
\text { countries, and } 0 \text { othe } \\
\text { before } 2000 \text {, and } 1 \text { oth } \\
\text { 3-month maturity reg } \\
\text { consistent standard e } \\
\text { are Newey-West hete } \\
\text { errors. }{ }^{*} \text { and }{ }^{* * *} \text { den }\end{array}$ & $\begin{array}{l}\text { y variable ta } \\
\text { wise. D2000 } \\
\text { erwise. Robus } \\
\text { ression, stand } \\
\text { rors ; for 1-y } \\
\text { oskedasticity } \\
\text { te significanc }\end{array}$ & $\begin{array}{l}\text { ing a value } \\
\text { s a dummy } \\
\text { t standard er } \\
\text { ard errors are } \\
\text { ar maturity } \\
\text { and autocorr } \\
\text { at } 10 \% \text { and }\end{array}$ & $\begin{array}{l}\text { for inflatio } \\
\text { able taking } \\
\text { are in paren } \\
\text { hite heteros } \\
\text { ression, stan }\end{array}$ & $\begin{array}{l}\text { targeting } \\
\text { value of } 0 \\
\text { heses. For } \\
\text { edasticity- } \\
\text { ard errors } \\
\text { standard } \\
\text { tively. }\end{array}$ \\
\hline
\end{tabular}

\subsection{Controlling for exchange rate management.}

The exchange rate strategy adopted by one country could impact on the relationship between IT and the UIP condition by means of the management of international capital flows (either by means of regulations, controls or active monetary policy). Indeed, inflation targeting is consistent with a flexible exchange rate regime; this may induce some limits on capital mobility so as to manage the exchange rate more or less stringently. The more effective are capital flows limitations, the less flexible is the exchange rate. Thus, the impact of IT on the UIP condition may reflect the influence of the degree of capital mobility on it. Testing for the robustness of the result previously obtained (that IT affects the UIP condition) requires taking into account the exchange rate strategy channel. In order to do so, we consider the following equation: 


$$
\begin{aligned}
\Delta s_{i t}^{k}= & \alpha_{i}+\beta\left(i_{i t}^{k}-i_{U S, t}^{k}\right)+\phi_{I T} I T_{i t} *\left(i_{i t}^{k}-i_{U S, t}^{k}\right) \\
& +\phi_{F L E X} F L E X_{i t} *\left(i_{i t}^{k}-i_{U S, t}^{k}\right)+\varepsilon_{i t}^{k}
\end{aligned}
$$

where $F L E X_{i t}$ is the index of exchange rate flexibility for country $i$ at period $t$. We measure this variable by means of the index provided by Reinhart and Rogoff (2004) and updated by Ilzetzki et al. (2011) up to 2010. This index ranges from 1 to 6 ; a higher index represents a more flexible exchange rate regime.

The results of the regression estimation of Equation (8) are reported in Table 4. These results show no evidence of an influence of exchange rate regime on the slope-coefficient in Fama's regression: the coefficient associated with $F L E X_{i t} *\left(i_{i t}^{k}-i_{U S, t}^{k}\right)$ is not significant at $10 \%$, at any maturity. The impact of IT remains significant at 5\%: the coefficient for $I T_{i t} *\left(i_{i t}^{k}-i_{U S, t}^{k}\right)$ varies from -0.726 to -0.725 for a three-month maturity and from -0.590 to -0.508 for a one-year maturity. Thus, we conclude that the result previously obtained is robust to the introduction of the exchange rate regime in the analysis.

\subsection{Inflation uncertainty.}

As mentioned above, there is strong evidence that adopting IT can help to reduce inflation uncertainty by lowering both inflation and its volatility. To examine the influence of IT through its impact on inflation uncertainty, a robustness investigation consists in replacing $I T$ by a measure of inflation uncertainty, as done in Bansal and Dahlquist (2000) to characterize developed and emerging countries. First we use as such a measure a dummy variable $(H I N F)$ that separates low inflationary countries/periods from moderate-tohigh inflationary countries/periods: HINF takes a value of 1 for moderateto-high inflation countries, and 0 otherwise. Since adopting IT leads to a decrease in inflation and there is a downward trend in inflation in emerging countries, each country is characterized by two values of inflation: average inflation before and after IT for targeters, and average inflation before and after 2000 (the average adoption date of IT) for non-targeters. The justification for this specification is that, as mentioned above, the Fisherian relation must hold if inflation exceeds a threshold characterized by the dummy variable $H I N F$. We define moderate-to-high inflation countries/periods as countries/periods characterized by an average annual inflation rate relative to the U.S. greater than the median on the whole dataset. Using an average measure across periods allows us to avoid endogeneity (reserve causality be- 
Table 4: Inflation targeting and the Fama regression, controlling for exchange rate flexibility

\begin{tabular}{lccccc}
\hline & \multicolumn{2}{c}{3 -month } & & \multicolumn{2}{c}{ 1-year } \\
\cline { 2 - 3 } \cline { 5 - 6 }$\left(i-i_{U S}\right)$ & $0.474^{* * *}$ & 0.447 & & $0.281^{* * *}$ & $0.814^{*}$ \\
& $(0.141)$ & $(0.533)$ & & $(0.089)$ & $(0.479)$ \\
$I T \times\left(i-i_{U S}\right)$ & $-0.726^{* * *}$ & $-0.725^{* * *}$ & & $-0.508^{* *}$ & $-0.590^{* * *}$ \\
& $(0.161)$ & $(0.154)$ & & $(0.199)$ & $(0.217)$ \\
$F L E X \times\left(i-i_{U S}\right)$ & & 0.005 & & -0.124 \\
& & $(0.091)$ & & $(0.110)$ \\
Const. & 6.222 & 6.593 & & 6.611 & 1.981 \\
& $(3.734)$ & $(4.787)$ & & $(5.250)$ & $(4.554)$ \\
Obs. & & & & \\
Time effects & 2,303 & 2,204 & & 1,961 & 1,865 \\
Country effects & Yes & Yes & & Yes & Yes \\
\hline \hline
\end{tabular}

Notes: $I T$ is a dummy variable taking a value of 1 for inflation targeting countries, and 0 otherwise. D2000 is a dummy variable taking a value of 0 before 2000, and 1 otherwise. Robust standard errors are in parentheses. For 3-month maturity regression, standard errors are White heteroskedasticityconsistent standard errors ; for 1-year maturity regression, standard errors are Newey-West heteroskedasticity and autocorrelation-consistent standard errors. ${ }^{*}$ and ${ }^{* * *}$ denote significance at $10 \%$ and $1 \%$ level, respectively.

tween exchange rate variation and inflation). We then consider the following equation:

$$
\Delta s_{i t}^{k}=\alpha_{i}+\beta\left(i_{i t}^{k}-i_{U S, t}^{k}\right)+\phi_{H I N F} H I N F_{i t} *\left(i_{i t}^{k}-i_{U S, t}^{k}\right)+\varepsilon_{i t}^{k}
$$

We expect to find $\phi_{H I N F}$ positive.

Second, we use inflation volatility as a measure of inflation uncertainty and we introduce a dummy variable ( $H I N F V O L)$ that takes a value of 1 for volatile inflation countries/periods, and 0 otherwise. Volatile inflation countries/periods are defined as countries/periods that have an inflation variance relative to the U.S. greater than the median on the whole dataset. We test for the following equation:

$$
\Delta s_{i t}^{k}=\alpha_{i}+\beta\left(i_{i t}^{k}-i_{U S, t}^{k}\right)+\phi_{H I N F V O L} H I N F V O L_{i t} *\left(i_{i t}^{k}-i_{U S, t}^{k}\right)+\varepsilon_{i t}^{k}
$$

We also expect to find $\phi_{H I N F V O L}$ positive. 
The estimations of equations (9) and (10) are reported in Tables 5 and 6 , respectively. The estimation of equation (9) in Table 5 shows that, whatever the maturity considered, the coefficient of interest rate differential is not significant while the coefficient of its interaction with the dummy variable $(H I N F)$ reflecting a moderate-to-high inflationary environment (average inflation over a given period ${ }^{4}$ for a given country exceeding the median average inflation relative to the U.S. obtained on the dataset on the entire time span, around 2.3 times the U.S. average inflation rate (2.63)) is significantly positive. More specifically, when the average inflation rate is less than $6.12 \%$, the slope coefficient is not significant. On the contrary, when the average inflation rate exceeds $6.12 \%$, the slope coefficient becomes significantly positive, but it is less than unity (the value when the UIP condition holds). This means that the Fisherian effects are present in low inflationary emerging countries and not in moderate-to-high inflation ones.

This finding is confirmed by Table 6 that reports the estimation of equation (10) considering the volatility of inflation instead of the average level of inflation. As shown by the results in Table 6, based on 3-month or 1-year maturity, the UIP condition does not hold if the volatility (standard deviation) of inflation is low (i.e. lower than the median rate, 2.68 times the U.S. level), but tends to hold otherwise.

Since it has been proved that IT contributes to the decrease of inflation uncertainty (measured by inflation level and volatility), the results obtained from the estimation of equations (9) and (10) sustain our conjecture that adopting IT is conducive to the FBP by lowering inflation uncertainty.

\subsection{Panel smooth transition regression.}

The definition of dummy variables in equations (9) and (10) is based on an arbitrary choice of a threshold. Strictly speaking, the relevant threshold should be agent-based. Thus, in a market with heterogeneous agents, heterogeneity in threshold occurs. In this case, as suggested by Teräsvirta (1994) and Granger and Lee (1999), time aggregation and non-synchronous adjustment by heterogeneous agents will tend to smooth aggregate regime switching. This suggests another robustness test: we consider an approach in which the threshold is endogenously determined. ${ }^{5}$ This approach is the panel smooth transition regression (PSTR) model developed by González et

\footnotetext{
${ }^{4}$ The periods are before and after IT for targeters and before and after 2000 for nontargeters.

${ }^{5}$ The non-linearity in Fama regression was investigated by Sarno et al. (2006) and Coudert and Mignon (2013) using a smooth transition regression approach.
} 
Table 5: Inflation and the Fama regression

\begin{tabular}{lccccc}
\hline & \multicolumn{2}{c}{3 -month } & & \multicolumn{2}{c}{ 1-year } \\
\cline { 2 - 3 } \cline { 5 - 6 }$\left(i-i^{*}\right)$ & $0.531^{* * *}$ & -0.108 & & $0.304^{* * *}$ & -0.203 \\
& $(0.154)$ & $(0.241)$ & & $(0.090)$ & $(0.223)$ \\
$H I N F L \times\left(i-i^{*}\right)$ & & $0.633^{* * *}$ & & $0.499^{* *}$ \\
& & $(0.178)$ & & $(0.210)$ \\
Const. & 5.676 & $6.350^{*}$ & & 6.811 & 6.727 \\
& $(3.665)$ & $(3.600)$ & & $(5.299)$ & $(5.223)$ \\
& & & & & \\
Obs. & 2,303 & 2,303 & & 1,961 & 1,961 \\
Time effects & Yes & Yes & & Yes & Yes \\
Country effects & Yes & Yes & & Yes & Yes \\
\hline \hline
\end{tabular}

Notes: HINFL is a dummy variable taking a value of 1 for moderate-to-high inflation countries (average annual inflation (relative to the U.S.) greater than the median on the whole dataset), and 0 otherwise. Robust standard errors are in parentheses. For 3-month maturity regression, standard errors are White heteroskedasticity-consistent standard errors ; for 1-year maturity regression, standard errors are Newey-West heteroskedasticity and autocorrelation-consistent standard errors. ${ }^{*}$ and ${ }^{* * *}$ denote significance at $10 \%$ and $1 \%$ level, respectively.

al. (2005), that is a generalization of the threshold panel model of Hansen (1999).

The panel smooth transition regression (PSTR) model is given by:

$$
\Delta s_{i t}^{k}=\alpha_{i}+\beta_{1}\left(i_{i t}^{k}-i_{U S, t}^{k}\right)+\beta_{2}\left(i_{i t}^{k}-i_{U S, t}^{k}\right) * G\left(q_{i t} ; \gamma ; c\right)+\varepsilon_{i t}^{k}
$$

Following González et al. (2005), the transition function is given by:

$$
G\left(q_{i t}, \gamma, c\right)=\left[1+\exp \left(-\gamma\left(q_{i t}-c\right)\right)\right]^{-1}
$$

where $G($.$) is a logistic transition function that is normalized and bounded$ between 0 and $1, q_{i t}$ is the transition variable, $\gamma$ stands for the slope parameter that determines the speed of transition between the two extreme regimes, $c$ is the threshold parameter.

In our case, the transition variable is a measure of inflation uncertainty (inflation level or inflation volatility, both relative to the U.S.). The link between the expected depreciation and the interest rate differential is characterized by two extreme regimes that are associated with low and high values of $q_{i t}$ with a single monotonic transition as $q_{i t}$ increases. More specifically, this is specified by a continuum of parameters $\left(\beta_{1}+\beta_{2} G\left(q_{i t} ; \gamma ; c\right)\right)$ that ranges 
Table 6: Inflation volatility and the Fama regression

\begin{tabular}{lccccc}
\hline & \multicolumn{2}{c}{3 -month } & & \multicolumn{2}{c}{ 1-year } \\
\cline { 2 - 3 } \cline { 5 - 6 } & $(1)$ & $(2)$ & & $(3)$ & $(4)$ \\
\hline$\left(i-i_{U S}\right)$ & $0.531^{* * *}$ & -0.224 & & $0.304^{* * *}$ & -0.095 \\
& $(0.154)$ & $(0.289)$ & & $(0.090)$ & $(0.206)$ \\
$H I N F L V O L \times\left(i-i_{U S}\right)$ & & $0.701^{* * *}$ & & & $0.383^{* *}$ \\
& & $(0.170)$ & & & $(0.187)$ \\
Const. & 5.676 & 6.284 & & 6.811 & 6.886 \\
& $(3.665)$ & $(3.735)$ & & $(5.299)$ & $(5.274)$ \\
& & & & & \\
Obs. & 2,303 & 2,303 & & 1,961 & 1,961 \\
Time effects & Yes & Yes & & Yes & Yes \\
Country effects & Yes & Yes & & Yes & Yes \\
\hline \hline
\end{tabular}

Notes: $H I N F V O L$ is a dummy variable taking a value of 1 for high volatile inflation countries (average annual inflation volatility (relative to the U.S) greater than the median on the whole dataset), and 0 otherwise. Robust standard errors are in parentheses. For 3-month maturity regression, standard errors are White heteroskedasticity-consistent standard errors ; for 1-year maturity regression, standard errors are Newey-West heteroskedasticity and autocorrelation-consistent standard errors. $*$ and ${ }^{* * *}$ denote significance at $10 \%$ and $1 \%$ level, respectively.

from $\beta_{1}$ in the first regime when $G()=$.0 to $\beta_{1}+\beta_{2}$ in the second regime when $G()=$.1 (See Figure 1). For the reason mentioned above, we expect to find $\beta_{2}$ positive.

Before estimating parameters in Equation (11) one must test for the presence of non-linearity. Testing the linearity against the PSTR model simply consists of testing $H_{0}: \gamma=0$ or $H_{0}^{\prime}: \beta_{2}=0$ in Equation (11). This test is not standard since under the null hypothesis the PSTR model contains unidentified nuisance parameters. To overcome this problem, the solution consists in replacing $G\left(q_{i t}, \gamma, c\right)$ by its first-order Taylor expansion around $\gamma=0$ and testing an equivalent hypothesis in this auxiliary regression.

$$
\Delta s_{i t}^{k}=\alpha_{i}+\beta_{1}^{*}\left(i_{i t}^{k}-i_{U S, t}^{k}\right)+\beta_{2}^{*}\left(i_{i t}^{k}-i_{U S, t}^{k}\right) q_{i t}+\varepsilon_{i t}^{* k}
$$

where $\beta_{2}^{*}$ is a multiple of $\gamma$. Testing $H_{0}: \gamma=0$ or $H_{0}^{\prime}: \beta_{2}=0$ in Equation (11) is equivalent to test $H_{0}^{*}: \beta_{2}^{*}=0$ in the auxiliary regression (13). Then a standard test like the Fisher-statistics can be used. ${ }^{6}$

\footnotetext{
${ }^{6}$ We consider the F-statistics of the test that has better size properties in small sample than the asymptotic $\chi^{2}$ based statistic (van Dijk et al., 2002).
} 
Figure 1: Slope coefficients as function of inflation uncertainty

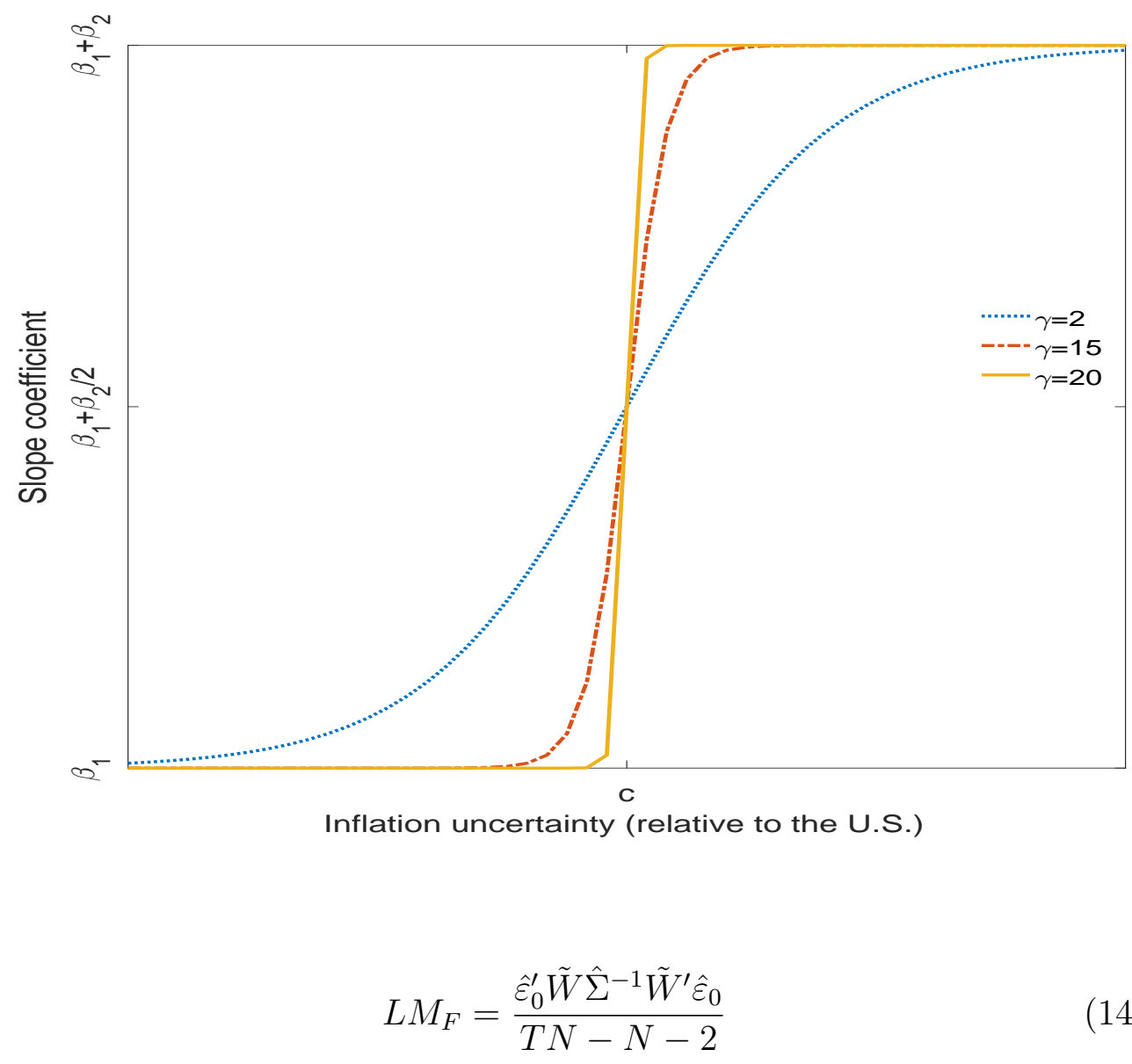

where $\hat{\varepsilon}_{0}$ is the vector of residual obtained under the null hypothesis of linearity, $\hat{\Sigma}=\left[-\tilde{W}^{\prime} \tilde{X}\left(\tilde{X}^{\prime} \tilde{X}\right)^{-1}: I\right] \hat{\Delta}\left[-\tilde{W}^{\prime} \tilde{X}\left(\tilde{X}^{\prime} \tilde{X}\right)^{-1}: I\right]^{\prime}$ in which $X$ is vector $\left(i_{i t}-i_{U S, t}\right), W$ is the vector $\left(i_{i t}-i_{U S, t}\right) q_{i t}, \tilde{X}$ and $\tilde{W}$ represent the fixed effects demeaning transformation of $X$ and $W, \hat{\Delta}$ is a consistent estimator of covariance matrix of $\tilde{Z}^{\prime} u / \sqrt{N}$ obtained from the constrained regression, where $Z=[Z, W]$. Under the null hypothesis $L M_{F}$ has an approximate $F(1, T N-N-2)$ distribution.

Tables 7 and 8 report the results of PSTR regression using inflation and inflation volatility as the transition variable, respectively. The results in Tables 7 and 8 clearly confirm the non-linearity in the Fama regression.

Let us first comment the results concerning inflation level as the transition variable (Table 7 ). The $L M_{F}$ test of linearity shows evidence of non-linearity at the conventional level of significance. ${ }^{7}$ Specifically, based on 3-month

${ }^{7}$ Further testing for no residual non-linearity shows that two regimes are sufficient to 
Table 7: Nonlinear Fama regression, transition variable=inflation

\begin{tabular}{lcc}
\hline & 3-month & 1-year \\
\hline Linearity test p-value & 0.033 & 0.046 \\
$\beta_{1}$ & 0.092 & 0.206 \\
& $(0.130)$ & $(0.184)$ \\
$\beta_{2}$ & $0.527^{* * *}$ & $0.317^{* *}$ \\
& $(0.116)$ & $(0.171)$ \\
$\beta_{1}+\beta_{2}$ & 0.619 & 0.523 \\
$c$ & 3.299 & 7.901 \\
$\gamma$ & 186.078 & 42.435 \\
\hline
\end{tabular}

Notes: The table reports the results from the PSTR Fama's regression where the transition variable is inflation. The test of linearity is implemented based on a Fisher statistic $\left(L M_{F}\right)$ using robust covariance matrix (with the null hypothesis of linearity). For $\beta_{1}$ and $\beta_{2}$, robust standard errors are in parentheses.

Table 8: Nonlinear Fama regression, transition variable=inflation volatility

\begin{tabular}{lcc}
\hline & 3-month & 1-year \\
\hline Linearity test p-value & 0.018 & 0.293 \\
$\beta_{1}$ & 0.127 & $0.276^{* *}$ \\
& $(0.118)$ & $(0.121)$ \\
$\beta_{2}$ & $0.497^{* * *}$ & $0.432^{* * *}$ \\
& $(0.102)$ & $(0.131)$ \\
$\beta_{1}+\beta_{2}$ & 0.624 & 0.708 \\
$c$ & 4.859 & 26.149 \\
$\gamma$ & 8.394 & 1.628 \\
\hline
\end{tabular}

Notes: The table reports the results from the PSTR

Fama's regression where the transition variable is inflation volatility. The test of linearity is implemented based on a Fisher statistic $\left(L M_{F}\right)$ using robust covariance matrix (with the null hypothesis of linearity). For $\beta_{1}$ and $\beta_{2}$, robust standard errors are in parentheses.

maturity, the threshold value of inflation relatively to the U.S. is around 3.30 , in the first regime, the slope coefficient is not significantly different from zero while in the second regime the slope coefficient is significantly positive $\left(\hat{\beta}_{1}+\hat{\beta}_{2}=0.619\right)$ but remains less than unity (as in UIP relation) (See Figure 2). Based on 1-year maturity, the threshold value of the relative inflation is around 7.901 and the slope coefficient is significantly positive only

capture the non-linearity pattern in the Fama regression. 
in the second regime $\left(\hat{\beta}_{1}+\hat{\beta}_{2}=0.708\right)$. Notice that the results based on the two maturities do not conflict since the threshold value is very high for 1-year maturity. Using the inflation level as a measure of inflation uncertainty, the Fisherian relation between expected depreciation and interest rate differential is weak in environment with low inflationary environment and tends to hold if inflation is high.

Let us now turn to the results concerning inflation volatility as the transition variable (Table 8). Using inflation volatility as transition, at $5 \%$ level of significance, there is also evidence of non-linearity in Fama regression for on 3 -month maturity with a threshold value that is around 4.86 and a parameter of the speed of transition that is relatively low (8.394). The estimated slope coefficients in the two regimes are very close to the estimated values using inflation as the transition variable. As before, using inflation volatility as a proxy for inflation uncertainty, there is a weak Fisherian relation between expected depreciation and interest rate differential when inflation volatility is low and this relation tends to be stronger when inflation volatility exceeds a certain threshold.

Figure 2 displays the estimated slope coefficients from PSTR model using inflation as the transition variable and based on 3-month maturity (the case of strong evidence of non-linearity). Before implementing IT, all targeters (except Korea and Thailand) were in the regime with high values of slope coefficient; and after adopting IT all move to the regime with low values of the slope coefficient. Prior to 2000, most of non-targeters (Argentina, Bulgaria, Croatia, Egypt, India, Pakistan, Russia, Sri Lanka and Venezuela) were in the regime with a high value of the slope coefficient; and after 2000, some of them (such as Argentina, Pakistan, Russia, Sri Lanka and Venezuela) remain in the high value regime. This finding is illustrated by the case of Brazil (a targeting country) and Argentina (a non-targeting country) in Figure 2.

\section{Conclusion.}

Many empirical studies provide evidence of the violation of the uncovered interest parity condition known as the forward bias puzzle. There is evidence of the forward premium puzzle (an extreme form of forward bias puzzle in which the forward discount points in the wrong direction) in developed countries. On the opposite, for emerging market countries, the forward premium puzzle is absent and on average the forward discount rate points in the right direction. The explanation commonly given is that emerging markets are probably riskier and characterized by high inflation uncertainty (Bansal and Dahlquist, 2000, Frankel and Poonawala, 2010) which leads to the absence 
Figure 2: Slope coefficients estimated by PSTR model

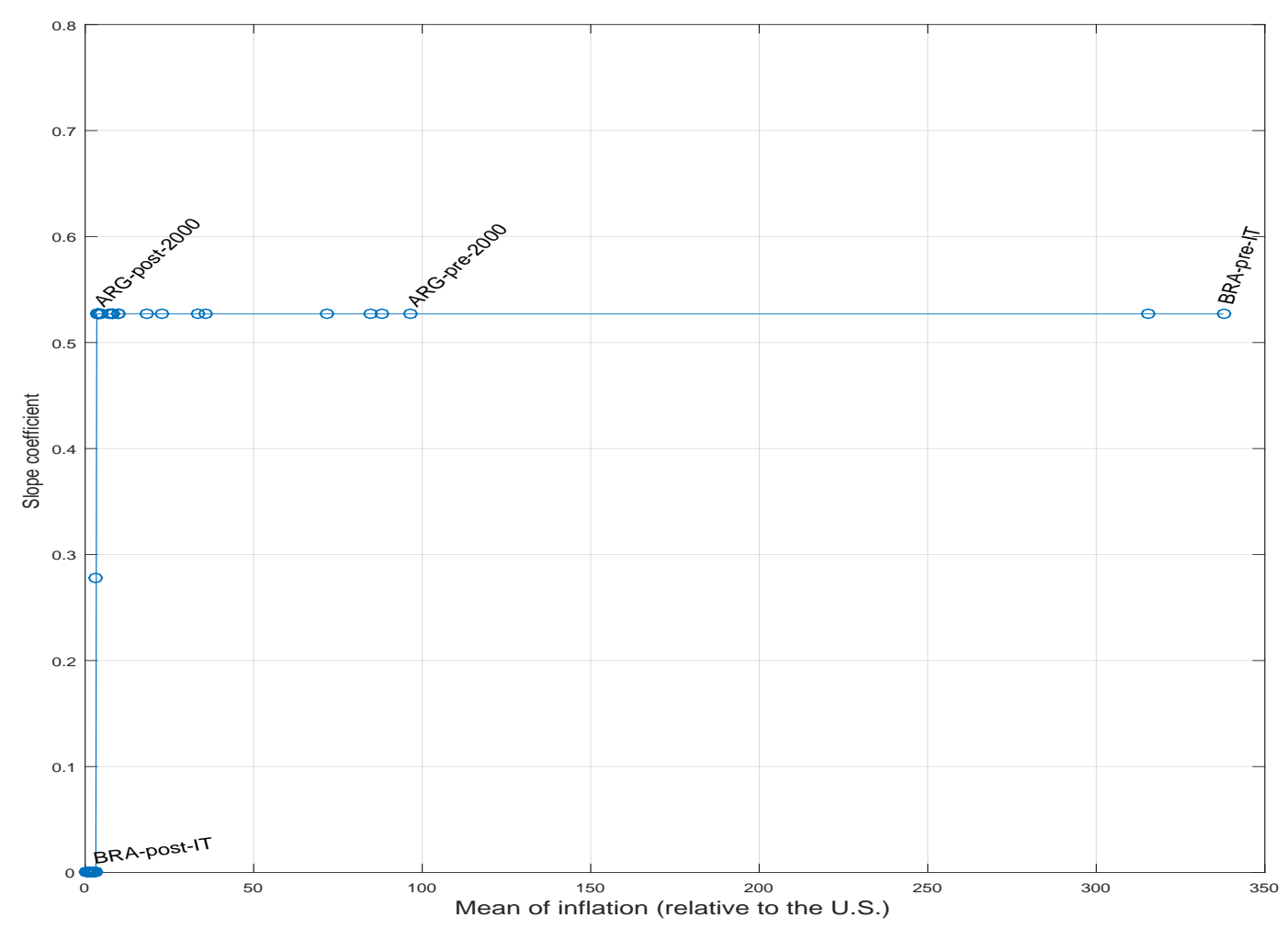

Notes: The figure represents the estimated slope-coefficient of Fama's regression using the mean of inflation relative to the U.S. (over period) as the transition variable. Each circle represents an observation.

of Fisherian effects.

In this paper, we examine whether adopting inflation targeting increases the forward bias in emerging countries by lowering inflation uncertainty. To this end, we consider quarterly data on 31 emerging countries (among which 16 are inflation targeting countries) from 1990Q1 to 2014Q3. Our results are consistent with the conjecture that the implementation of inflation targeting in emerging countries is conducive to the forward bias by weakening the Fisherian relation between expected depreciation and the interest rate differential (UIP condition). We show that this results from the fact that IT helps to reduce inflation uncertainty (defined as inflation level or volatility), increasing the effect of non-Fisherian fundamentals. Our finding holds after controlling for country-specific effects, time-specific effects, global disinflation, exchange rate management and using different econometric techniques.

An implication of our results for international finance theorists is that the performance of inflation targeting in emerging countries is associated with 
a larger violation of uncovered interest parity condition. An implication for macroeconomists and policymakers is that inflation targeting changes the informational content of exchange rates. This should lead to a closer attention to their dynamics. 


\section{References}

Baillie, Richard T. and Tim Bollerslev, 2000, "The Forward Premium Anomaly is Not as Bad as You Think," Journal of International Money and Finance, Vol. 19, No. 4, pp. 471-88.

Ball, Laurence M. and Niamh Sheridan, 2006, "Does Inflation Targeting Matter?" In Bernanke, Ben S. and Michael Woodford (eds.) The InflationTargeting Debate (National Bureau of Economic Research Studies in Income and Wealth), University of Chicago Press.

Bansal, Ravi, 1997, "An Exploration of the Forward Premium Puzzle in Currency Markets," Review of Financial Studies, Vol. 10, No. 2, pp. 369403.

Bansal, Ravi and Magnus Dahlquist, 2000, "The Forward Premium Puzzle: Different Tales from Developed and Emerging Economies," Journal of International Economics, Vol. 51, No. 1, pp. 115-44.

Bernanke, Ben S. and Frederic S. Mishkin, 1997, "Inflation Targeting: A New Framework of Monetary Policy?" Journal of Economic Perspectives, Vol. 11, No. 2, pp. 97-116.

Chinn, Menzie D. and Guy Meredith, 2004. Monetary Policy and LongHorizon Uncovered Interest Parity. IMF Staff Papers, Vol. 51, No. 3, pp. 409-30.

Coudert, Virginie and Valérie Mignon, 2013, "The "Forward Premium Puzzle" and the Sovereign Default Risk," Journal of International Money and Finance, Vol. 32, pp. 491-511.

De Mendonça, Helder Ferreira and Gustavo José de Guimarães e Souza., 2012, "Is Inflation Targeting a Good Remedy to Control Inflation?" Journal of Development Economics, Vol. 98, No. 2, pp. 178-91.

Fama, Eugene F., 1984, "Forward and Spot Exchange Rates," Journal of Monetary Economics, Vol. 14, No. 3, pp. 319-38.

Farhi, Emmanuel and Xavier Gabaix, 2016, "Rare Disasters and Exchange Rates," The Quarterly Journal of Economics, Vol. 131, No. 1, pp. 1-52.

Frankel, Jeffrey and Jumana Poonawala, 2010, "The Forward Market in Emerging Currencies: Less Biased than in Major Currencies," Journal of International Money and Finance, Vol. 29, No. 3, pp. 585-98.

Fuerst, Timothy S., 1992, "Liquidity, Loanable Funds, and Real Activity," Journal of Monetary Economics, Vol. 29, No. 1, pp. 3-24.

Gonçalves, Carlos Eduardo S. and João M. Salles., 2008, "Inflation Targeting in Emerging Economies: What Do the Data Say?" Journal of Development 
Economics, Vol. 85, No. 1, pp. 312-18.

González, Andrés, Timo Teräsvirta and Dick van Dijk, 2005, "Panel Smooth Transition Regression Models," Research Paper No. 165, Quantitative Finance Research Centre, University of Technology, Sydney.

Granger, Clive WJ and Tae-Hwy Lee, 1999, "The Effect of Aggregation on Nonlinearity," Econometric Reviews, Vol. 18, No. 3, pp. 259-69.

Hansen, Bruce E., 1999, "Threshold Effects in Non-Dynamic Panels: Estimation, Testing and Inference," Journal of Econometrics, Vol. 93, No. 2, pp. 345-68.

Ilzetzki, Ethan, Carmen M. Reinhart and Kenneth S. Rogoff, 2011, "Exchange Rate Arrangements Entering the 21st Century: Which Anchor Will Hold?" Unpublished, University of Maryland and Harvard University.

Ito, Hiro and Menzie Chinn, 2007, "Price-Based Measurement of Financial Globalization: A Cross-Country Study of Interest Rate Parity," Pacific Economic Review, Vol. 12, No. 4, pp. 419-44.

Lin, Shu and Haichun Ye, 2007, "Does Inflation Targeting Really Make a Difference? Evaluating the Treatment Effect of Inflation Targeting in Seven Industrial Countries,", Journal of Monetary Economics, Vol. 54, No. 8, pp. 2521-33.

Lin, Shu and Haichun Ye, 2009, "Does Inflation Targeting Make a Difference in Developing Countries?" Journal of Development Economics, Vol. 89, No. 1, pp. 118-23.

Lucas, Robert E., 1990, "Liquidity and Interest Rates," Journal of Economic Theory, Vol. 50, No. 2, pp. 237-62.

Mishkin, Frederic S, 2000, "Inflation Targeting in Emerging-Market Countries," American Economic Review, Vol. 90, No. 2, pp. 105-09.

Mishkin, Frederic S. and Klaus Schmidt-Hebbel, 2007, "Does Inflation Targeting Make a Difference?" National Bureau of Economic Research, NBER Working Paper 12876.

Reinhart, Carmen M. and Kenneth S. Rogoff, 2004, "The Modern History of Exchange Rate Arrangements: A Reinterpretation," Quarterly Journal of Economics, Vol. 119, No. 1, pp. 1-48.

Rose, Andrew K., 2007, "A Stable International Monetary System Emerges: Inflation Targeting is Bretton Woods, Reversed," Journal of International Money and Finance, Vol. 26, No. 5, pp. 663-81.

Sarno, Lucio, Giorgio Valente and Hyginus Leon, 2006, "Nonlinearity in Deviations from Uncovered Interest Parity: An Explanation of the Forward Bias Puzzle," Review of Finance, Vol. 10, No. 3, pp. 443-82. 
Svensson, Lars EO, 1997, "Inflation Forecast Targeting: Implementing and Monitoring Inflation Targets," European Economic Review, Vol. 41, No. 6, pp. 111-46.

Teräsvirta, Timo, 1994, "Specification, Estimation and Evaluation of Smooth Transition Autoregressive Models," Journal of the American Statistical Association, Vol. 89, No. 425, pp. 208-18.

Dijk, Dick van, Timo Teräsvirta and Philip Hans Franses, 2002, "Smooth Transition Autoregressive Models: A Survey of Recent Developments," Econometric Reviews, Vol. 21, No. 1, pp. 1-47.

Vega, Marco and Diego Winkelried, 2005, "Inflation Targeting and Inflation Behavior: A Successful Story?" International Journal of Central Banking, Vo. 3, pp. 153-75. 